\title{
第二世代ウェーブレット変換を用いた 路面凹凸検出方法の基礎的研究
}

\author{
白川龍生 ${ }^{1}$. 川村 彰 $^{2}$. 中过 隆 $^{3} \cdot$ 上浦正樹 $^{4}$ \\ ${ }^{1}$ 正会員 北見工業大学 工学部土木開発工学科 (广090-8507 北見市公園町 165) \\ 2 正会員 工博 北見工業大学助教授 工学部土木開発工学科 (广 090-8507 北見市公園町 165) \\ ${ }^{3}$ 正会員 工博 北海道大学大学院助教授 工学研究科 ( \\ ${ }^{4}$ 正会員 工博 北海学園大学教授 工学部土木工学科 (
}

\begin{abstract}
路面性状は, 車と路面の相互作用に関わる諸問題と密接に関わるため, 評価の基礎となる路面プロファ イルデータ処理方法の確立は今日の重要な課題となっている.本研究は, 路面プロファイルデータから特 徵的な形状を抽出するためのデータ処理方法として , パラメータ学習機能を有する第二世代ウェーブレッ 卜変換 (SWT) に着目し, PIARC EVEN データを用いて特徵的な形状の学習及び検出方法について基礎的 な研究を行なった．兴の結果，SWT は学習したトレーニング信号との相関係数がデータに重み付けされる ため，これまで振幅が小さく不明瞭だった波形をクローズアップできる一方，形状が大きく異なる成分は 特徵点として検出しない．これは路面管理目的に応じた基底関数を設計する上で重要な性質と考えられる．
\end{abstract}

Key Word : Second Generation Wavelets, Learning and Detection Theory, Road Roughness

1 .はじめに

路面性状は，車の操縦性，乗り心地など道路利用 者の安全性及び快適性に関わる諸問題と密接に関わ っており，路面性状評価の基礎となる路面縦断プロ ファイル (以下，「路面プロファイル」という) デ 一夕処理方法の確立は極めて重要な課題である ${ }^{1), 2)}$.

路面プロファイル上に局在する凹凸を識別する方 法としては，発生位置及び空間周波数情報を同時に 識別できるウェーブレット変換 (Wavelet Transform , 以下，「WT」という) が注目されるようになった ${ }^{2)}$

従来のスペクトル解析では, 空間領域のデータ を周波数領域へ変換する際に路面凹凸の発生位置に 関する情報が不明確となるほか，局在する路面凹凸 の影響により，平均的な路面プロファイル特性が歪 められて表現される場合が見受けられ

る ${ }^{2), 3)}$.

WT の長所は，（1）周波数領域で信号を表現す るフーリエ変換の性質に加え, 変動の空間的推移も 同時に把握でき，(2) 初期の段階で決定する分解・ 再構成アルゴリズムが全計算過程で同一であり，高 速演算が可能なことである.このため,WT は音響・ 画像信号処理をはじめ, 数多くの工学的分野で用い られるようになった（ISO 15444 で規格された画像
圧縮技術の JPEG 2000 (代表的な応用例である)． 路面性状評価への WT の適用に関する研究は, 近年 精力的に行なわれており，従来困難であった路面プ ロファイル上に局在する損失データの処理, 評価に 有効であることが示されている2，4)-6) .

一方, WT の短所として, (1) 空間領域（位置 情報) の分解性能は高いが, 周波数領域の分解性能 は高周波帯域で急速に劣化するため, 特定の周波数 成分の空間領域における変化は検出が困難であり，

(2) 基底関数と呼ばれる特殊な信号の構成要素に 分解するため, 種類の選択方法によっては出力結果 (形状及び特徵点の検出など) が大きく異なること が挙げられる.このうち (1) については, 高周波 成分の分解性能を高めたウェーブレットパケット変 換か開発されており，必要によりこの方法を用いる とよい5)。(2) については, 必要なデータの性質 に応じた基底関数を設計または選択することによっ て問題を回避できる.しかし, 基底関数は直交条件 (モーメント・コンディション) など，樣々な制約 条件を満足する必要があり，設計は容易ではない． また Daubechies など広く知られている基底関数の場 合, 路面凹凸の形状に類似したものは少なく, 現状 では最適な基底関数の選択についても困難であ $\left.3^{2)}, 4\right)$-6). 
上記のように，路面性状評価における WT の適用 については基底関数の最適化が最大の課題であった が，1996 年に W. Sweldens によって従来の WT に パラメータの学習機能を付加した Lifting Scheme 法 が発表されて以降，これまでのWT の問題点が解消 されつつある ・特に高野らの研究によって自由パ ラメータを導入した WT が「第二世代ウェーブレッ 卜変換」(以下，「SWT」という) として体系化さ れ，基底関数の最適化処理が飛躍的に向上した ${ }^{81,9)}$.

本研究は, SWT を路面維持管理へ適用するため の基礎的な研究を行なった．SWT の有効性を検証 するため，(1) 路面プロファイルデータ (特徵的 な路面凹凸を含む）から自由パラメータを学習し，

(2) 特徵的な形状と類似した成分を検出する方法 について考察した . また, 特徵点検出のためのSWT の別解法を考案したので，併せて報告する．なお， 研究に用いた路面プロファイルデータは，1998 年 に世界道路協会 (以下，「PIARC」という) による 国際共同試験（以下，「EVEN」という）結果の一

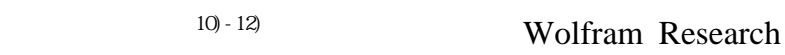
社の Mathematica を用いた ${ }^{13)}$.

\section{2 . 第二世代ウェーブレット変換の概要}

（1）第二世代ウェーブレット変換とは2 ${ }^{2,4)-9)}$

WT は, 入力データに含まれる周波数帯域 (角周 波数 0 ח の領域) を低周波及び高周波分解フィル タによって 2 等分し, 同時にダウンサンプリング操 作によって解像度を $1 / 2$ 倍する演算を低域通過成分 について展開する演算方法である。

入力信号 $\left(c_{l}^{1}\right)$ は, 分解フィルタによって式(1)， (2)のように分解される .

$$
\begin{aligned}
& \hat{c}_{k}^{0}=\sum_{l} \tilde{h}_{k, l}^{\text {old }} c_{l}^{1} \\
& \hat{d}_{m}^{0}=\sum_{l} \tilde{g}_{m, l}^{\text {old }} c_{l}^{1}
\end{aligned}
$$

ここに $\hat{c}_{k}^{0}:$ 低周波成分

$\hat{d}_{m}^{0}:$ 高周波成分

$\tilde{h}_{k, l}^{\text {old }}:$ 低周波分解フィルタ

$\tilde{g}_{m, l}^{o l d}:$ 高周波分解フィルタ

$l:$ 解像度 (周波数) パラメータ

$k:$ 位置パラメータ (低周波成分)

$m:$ 位置パラメータ (高周波成分) $\tilde{h}_{k, l}^{\text {old }}$ 及び $\tilde{g}_{m, l}^{\text {old }}$ は, 基底関数の種類により性能が異 なる

$c_{l}^{1}$ は $\hat{c}_{k}^{0}, \hat{d}_{m}^{0}$ より以下のように再構成することが できる .

$$
c_{l}^{1}=\sum_{k} h_{k, l}^{\text {old }} \hat{c}_{k}^{0}+\sum_{m} g_{m, l}^{\text {old }} \hat{d}_{m}^{0}
$$

ここに $h_{k, l}^{\text {old }}:$ 低周波復元フィルタ

$g_{m, l}^{\text {old }}:$ 高周波復元フィルタ

フィルタには以下の条件が与えられる .これを双 直交条件 (biorthogonal conditions) という.

$$
\begin{array}{ll}
\sum_{l} h_{k, l}^{\text {old }} \tilde{h}_{k^{\prime}, l}^{\text {old }}=\delta_{k k^{\prime}}, & \sum_{l} g_{m, l}^{\text {old }} \tilde{h}_{k, l}^{\text {old }}=0, \\
\sum_{l} h_{k, l}^{\text {old }} \tilde{g}_{m, l}^{\text {old }}=0, & \sum_{l} g_{m, l}^{\text {old }} \tilde{g}_{m^{\prime}, l}^{\text {old }}=\delta_{m m^{\prime}}
\end{array}
$$

SWT は, 上述の WT に自由パラメータを与えた ものであり，次式によって定義される．

$$
\begin{aligned}
& h_{k, l}=h_{k, l}^{\text {old }}+\sum_{m} \tilde{s}_{k, m} g_{m, l}^{\text {old }} \\
& \tilde{h}_{k, l}=\tilde{h}_{k, l}^{\text {old }} \\
& g_{m, l}=g_{m, l}^{\text {old }} \\
& \tilde{g}_{m, l}=\tilde{g}_{m, l}^{\text {old }}-\sum_{m} \tilde{s}_{k, m} \tilde{h}_{k, l}^{\text {old }}
\end{aligned}
$$

ここに $h_{k, l}$ : 新しい低周波復元フィルタ

$\tilde{h}_{k, l}:$ 新しい低周波分解フィルタ

$g_{m, l}:$ 新しい高周波復元フィルタ

$\tilde{g}_{m, l}:$ 新しい高周波分解フィルタ

$\tilde{s}_{k, m}:$ 自由パラメータ

SWT は， $\tilde{s}_{k, m}$ を調整することにより，信号に適応 する新しいフィルタを構成することができる．双直 交条件は以下のようになる .

$$
\begin{array}{ll}
\sum_{l} h_{k, l} \tilde{h}_{k^{\prime}, l}=\delta_{k k^{\prime}}, & \sum_{l} g_{m, l} \tilde{h}_{k, l}=0, \\
\sum_{l} h_{k, l} \tilde{g}_{m, l}=0, & \sum_{l} g_{m, l} \tilde{g}_{m^{\prime}, l}=\delta_{m m^{\prime}}
\end{array}
$$

(2)特徵点の検出と自由パラメータの学習方法 ${ }^{8), 9}$ SWT は, 信号の特定部分 (特徵的な形状) を 検出するため， $\tilde{s}_{k, m}$ を用いて特徵点における高周 波成分 $\left(d_{m}^{0}\right)$ を 0 とする演算を行なう. 
WT における $\hat{d}_{m}^{0}$ の絶対値から $d_{m}^{0}$ の絶対值を差 引くと, 特徵的な形状と異なる箇所では值が小さ くなるが, 類似箇所ではほとんど変化しない． SWT は，この重み付けによって特徵的な形状の 箇所を容易に検出することができる (式(7)) .

$$
\begin{gathered}
I_{m}=\left|\hat{d}_{m}^{0}\right|-\left|d_{m}^{0}\right| \\
\text { ここに } I_{m}:\left|\hat{d}_{m}^{0}\right| \text { と }\left|d_{m}^{0}\right| \text { の差 } \\
\text { ここで, } d_{m}^{0} \text { は式(8)によって求める. } \\
d_{m}^{0}=\sum_{l} \tilde{g}_{m, l} c_{l}^{1} \\
=\sum_{l}\left(\tilde{g}_{m, l}^{\text {old }}-\sum_{k} \tilde{s}_{k, m} \tilde{h}_{k, l}^{\text {old }}\right) c_{l}^{1} \\
=\hat{d}_{m}^{0}-\sum_{k} \hat{c}_{k}^{0} \tilde{s}_{k, m}
\end{gathered}
$$

特徵点では, $d_{m}^{0}$ が 0 となるため，

$$
d_{m}^{0}=\hat{d}_{m}^{0}-\sum_{k} \hat{c}_{k}^{0} \tilde{s}_{k, m}=0
$$

$\tilde{s}_{k, m}$ は, 特徵的な形状を有するトレーニング信 号 (以下, 「 $\mathrm{TS}\lrcorner$ という) を $v=2 n$ 個用意し， 式(10)によって学習すると効率的である .

$$
\begin{gathered}
\sum_{k=m-n}^{m+n} \hat{c}_{k}^{0, v} \tilde{s}_{k, m}-\hat{d}_{m}^{0, v}=0, \quad v=1,2, \ldots, 2 n \\
\hat{c}_{k}^{0, v}=\sum_{l} \tilde{h}_{k, l}^{\text {old }} c_{l}^{1, v}, \hat{d}_{m}^{0, v}=\sum_{l} \tilde{g}_{m, l}^{\text {old }} c_{l}^{1, v}
\end{gathered}
$$

さらに,式(10)に $\tilde{g}_{m, l}$ の総和が 0 となる条件を 加える.すなわち，

$$
\begin{gathered}
\sum_{l} \tilde{g}_{m, l}=\sum_{l}\left(\tilde{g}_{m, l}^{\text {old }}-\sum_{k=m-n}^{m+n} \tilde{s}_{k, m} \tilde{h}_{k, l}^{\text {old }}\right)=0 \\
\text { こで, } \tilde{g}_{m, l}^{\text {old }} \text { が } \sum_{l} \tilde{g}_{m, l}^{\text {old }}=0 \text { と } \sum_{l} \tilde{h}_{m, l}^{\text {old }}=\text { const. } \text {. 定 }
\end{gathered}
$$

数)を満足させるならば, この条件は式(11)と等し い。

$$
\sum_{k=m-n}^{m+n} \tilde{s}_{k, m}=0
$$

式(10)及び式(11)から，式(12)を導出することが できる．式(12)を展開することにより， $\tilde{s}_{k, m}$ を求
めることができる .

$$
\left[\begin{array}{ccccc}
\hat{c}_{m-n}^{0,1} & \hat{c}_{m-n+1}^{0,1} & \cdot & \cdot & \hat{c}_{m+n}^{0,1} \\
\hat{c}_{m-n}^{0,2} & \hat{c}_{m-n+1}^{0,2} & \cdot & \cdot & \hat{c}_{m+n}^{0,2} \\
\cdot & \cdot & \cdot & \cdot & \cdot \\
\hat{c}_{m-n}^{0,2 n} & \hat{c}_{m-n+1}^{0,2 n} & \cdot & \cdot & \hat{c}_{m+n}^{0,2 n} \\
1 & 1 & \cdot & \cdot & 1
\end{array}\right]\left[\begin{array}{c}
\tilde{s}_{m-n, m} \\
\tilde{s}_{m-n+1, m} \\
\cdot \\
\tilde{s}_{m+n-1, m} \\
\tilde{s}_{m+n, m}
\end{array}\right]=\left[\begin{array}{c}
\hat{d}_{m}^{0,1} \\
\hat{d}_{m}^{0,2} \\
\cdot \\
\hat{d}_{m}^{0,2 n} \\
0
\end{array}\right]
$$

(3) 特徵点の検出手順 ${ }^{8), 9}$ 特徵点の検出手順を整理すると以下のようになる .

1) $\hat{d}_{m}^{0}$ の算出 (式(2))

2) データの分析目的に応じた TS を選定

3) $\tilde{s}_{k, m}$ を学習 (式(12))

4) $d_{m}^{0}$ の算出 (式(8))

5) $I_{m}$ の算出 (式(7))

\section{(4) 特徵点検出の別解法 ${ }^{8), 9)}$}

本研究では, $\tilde{g}_{m, l}$ を設計することなく, 特徵点を 検出する別解法を以下のように考案した .

式(8)を考察すると, WT によって $\hat{d}_{m}^{0}$ 及び $\hat{c}_{k}^{0}$ を求 め，2. (2) の手順により $\tilde{s}_{k, m}$ が得られれば， $c_{l}^{1} の$ 各点で $d_{m}^{0}$ を求めることができる.このため, 実用 的な演算レベルの場合, $\tilde{g}_{m, l}$ の構成は不要と思われ る .

また， $d_{m}^{0}$ の積分演算は一般的な表計算ソフトウ エアで実現でき，このことは式(7)の計算を行なう上 でも有利と考えられる．したがって，特徽点の検出 を目的とする場合は，本節で提案する別解法が実用 的と思われる .

\section{3. 路面凹凸の検出方法}

本章では, SWT を用いた自由パラメータの学習 方法及び TS に類似した路面凹凸の検出方法につい て考察する。

(1) 研究に用いるデータ

本研究では, PIARCによって公開されている EVEN 試験データの一部を用いた . EVEN試験とは， 


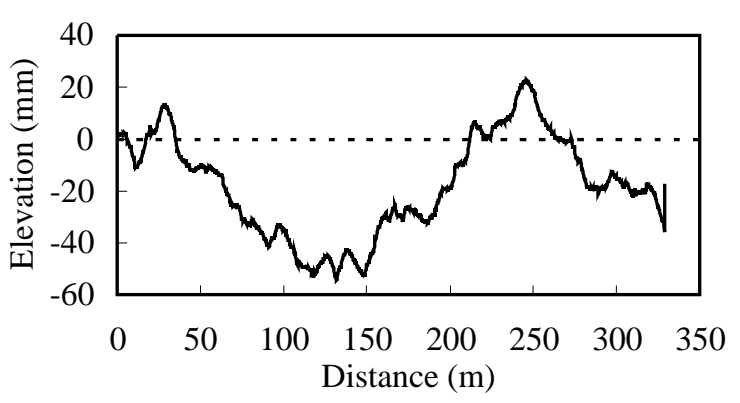

图-1 入力信号 $c_{l}^{1}$

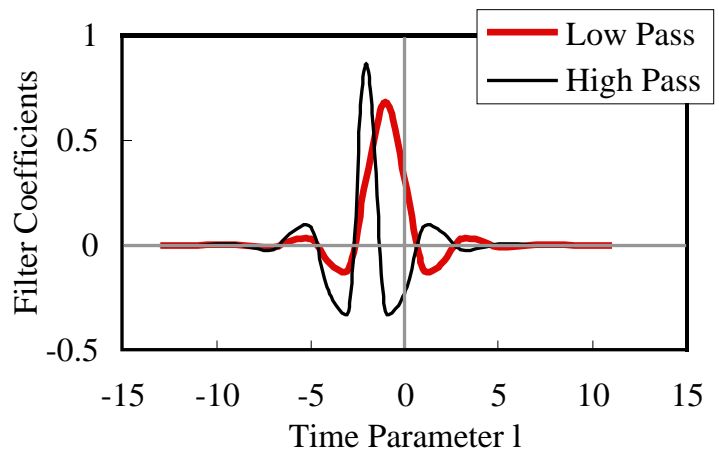

図- 2 基底関数（Spline $\mathrm{N}=2 ）$

各種プロファイラから得られた結果の調和を目的と して実施された試験である.本研究は日本で行なわ れた試験における区間 No.3 の真のプロファイル (以下，「True Profile」という) を用いた ${ }^{10)-12)}$.

True Profile は, 水準測量, The Rolling Dipstick 及 び the Static Dipstickによって構成されており，サン プリング周波数は Wave Number（以下，「WN」と いう) $=20 \mathrm{~m}^{-1}$ と高いため, 非常に幅広い周波数情 報が含まれている．

乥こで本研究では, 一例として, True Profile から 乗用車のバネ下固有振動数に相当する周波数帯域 (10 17Hz: 自動車の走行安全性に関係する周波数 帯域)を抽出し，この中から TS を選出することと した ${ }^{14)}$.また，事前処理としてWTによる4 段階の 成分分解を行い，一定の周波数帯域( $\left.\mathrm{WN}=0 \sim 125 \mathrm{~m}^{-1}\right)$ を抽出した．この成分を $c_{l}^{1}$ とし，图-1に示す．ま た，基底関数は双直交基底である Spline $\mathrm{N}=2$ を用い た (図-2) 2),4),5).

\section{( 2 ) 自由パラメータの学習}

特徵点を抽出するため, 入力信号 $c_{l}^{1}$ を式(1) 及び 式(2)によって $\hat{c}_{m}^{0} ， \hat{d}_{m}^{0}$ に分解する.$\hat{d}_{m}^{0}$ を図-3に

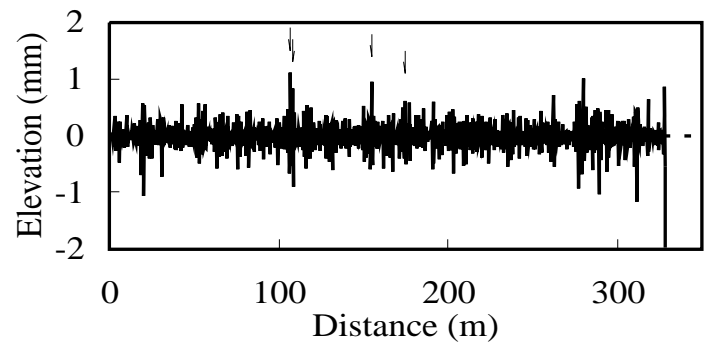

図-3 高周波成分 $\hat{d}_{m}^{0}$ (矢印は $\tilde{s}_{k, m}$ の学習区間)

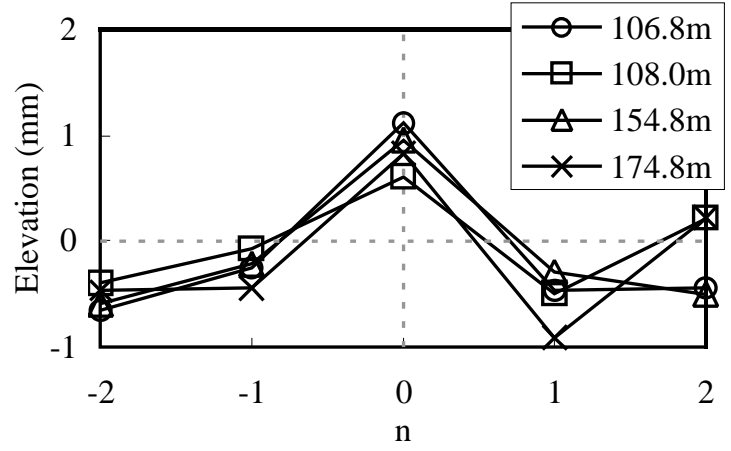

図- 4 トレーニング信号 TS $\left(\gamma_{m-2}^{n} \sim \gamma_{m+2}^{n}\right)$

表-1 学習した自由パラメータ $\tilde{s}_{k, m}$

\begin{tabular}{|c|c|}
\hline $\mathrm{k}$ & $\tilde{s}_{k, m}$ \\
\hline $\mathrm{m}-2$ & -1.336 \\
$\mathrm{~m}-1$ & 2.980 \\
$\mathrm{~m}$ & -2.797 \\
$\mathrm{~m}+1$ & 1.746 \\
$\mathrm{~m}+2$ & -0.594 \\
\hline
\end{tabular}

示す. 本研究では, $\hat{d}_{m}^{0}$ の振幅 (波高) が大きい地 点を上位 10 箇所抽出し, この地点付近の波形か類 似している 4 箇所 $(v=1,2,3,4)$ 付近を TS として 設定した (図-4) 8),9) . 式(12)へ代入すると以下のよ うになる。

$\left[\begin{array}{ccccc}\hat{c}_{m-2}^{0,1} & \hat{c}_{m-1}^{0,1} & \hat{c}_{m}^{0,1} & \hat{c}_{m+1}^{0,1} & \hat{c}_{m+2}^{0,1} \\ \hat{c}_{m-2}^{0,2} & \hat{c}_{m-1}^{0,2} & \hat{c}_{m}^{0,2} & \hat{c}_{m+1}^{0,2} & \hat{c}_{m+2}^{0,2} \\ \hat{c}_{m-2}^{0,3} & \hat{c}_{m-1}^{0,3} & \hat{c}_{m}^{0,3} & \hat{c}_{m+1}^{0,3} & \hat{c}_{m+2}^{0,3} \\ \hat{c}_{m-2}^{0,4} & \hat{c}_{m-1}^{0,4} & \hat{c}_{m}^{0,4} & \hat{c}_{m+1}^{0,4} & \hat{c}_{m+2}^{0,4} \\ 1 & 1 & 1 & 1 & 1\end{array}\right]\left[\begin{array}{c}\tilde{s}_{m-2, m} \\ \tilde{s}_{m-1, m} \\ \tilde{s}_{m, m} \\ \tilde{s}_{m+1, m} \\ \tilde{s}_{m+2, m}\end{array}\right]=\left[\begin{array}{c}\hat{d}_{m}^{0,1} \\ \hat{d}_{m}^{0,2} \\ \hat{d}_{m}^{0,3} \\ \hat{d}_{m}^{0,4} \\ 0\end{array}\right]$

$\tilde{s}_{k, m}$ の算出結果を表-1に示す． 


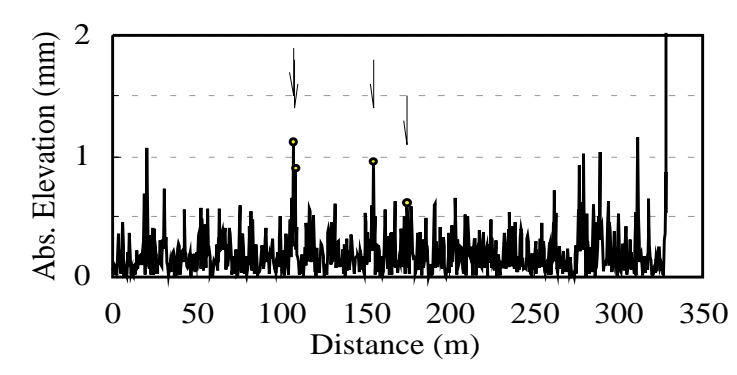

(a . 1) $\left|\hat{d}_{m}^{0}\right|$

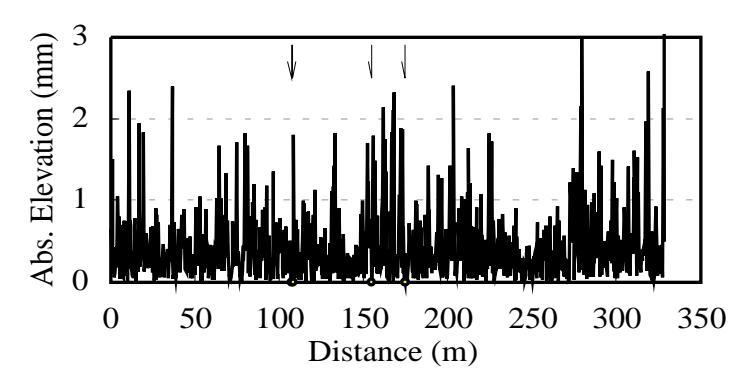

(b . 1) $\left|d_{m}^{0}\right|$

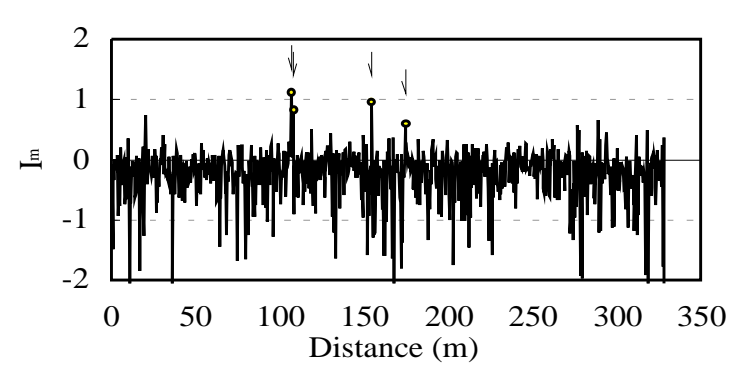

(c . 1) $I_{m}=\left|\hat{d}_{m}^{0}\right|-\left|d_{m}^{0}\right|$

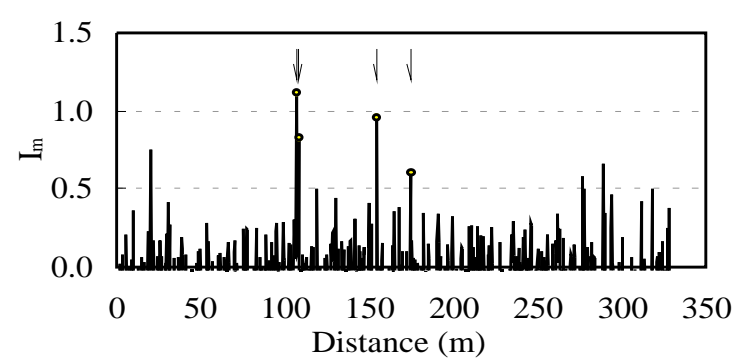

(d. 1) $I_{m} \geq 0$

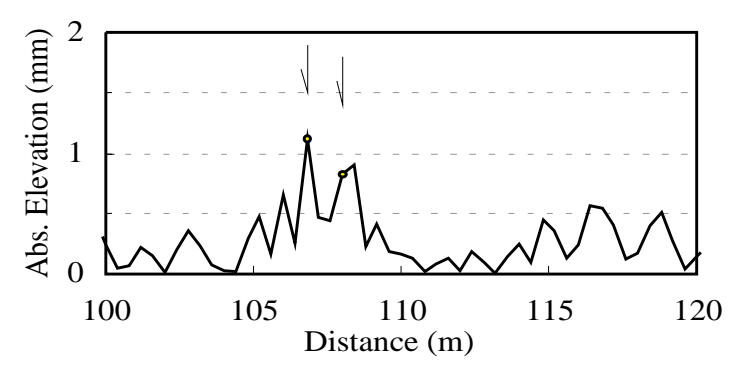

(a . 2) $\left|\hat{d}_{m}^{0}\right|$ (一部拡大)

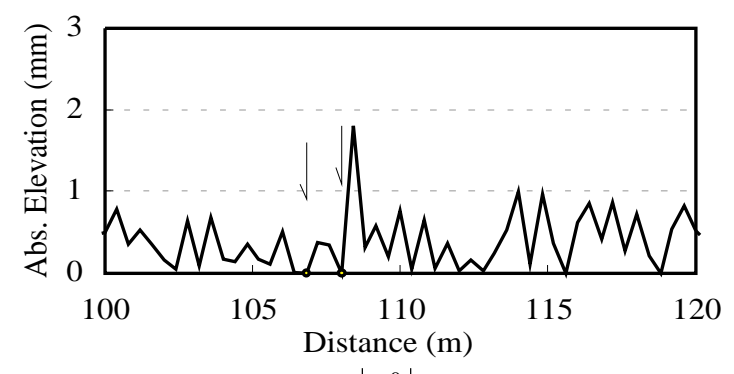

(b . 2) $\left|d_{m}^{0}\right|$ (一部拡大)

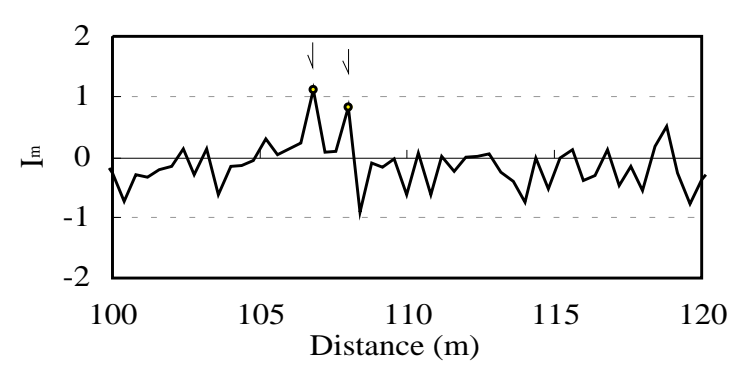

(c . 2) $I_{m}$ (一部拡大)

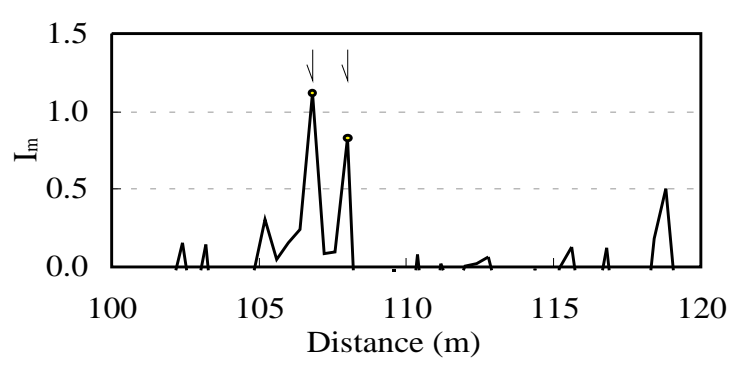

(d.2) $I_{m} \geq 0$ (一部拡大)

图- 5 特徵点の検出

\section{( 3 ) 特徵点の検出}

$\tilde{s}_{k, m}$ が求まると，2. (4) の方法を用いて特徵点 を検出することができる (図-5) 。図中，TS とし て設定した箇所を矢印及び○印で示した。

図-5(a. 1)，( a. 2) は， $\left|\hat{d}_{m}^{0}\right|$ の波形を示しており， これは従来の WT の演算結果と同值である. 始点か らの距離 260 320m 付近では, 振幅が $0.5 \mathrm{~mm}$ 以上
の箇所が多く見受けられる (図-5(a.1) ) .

図-5(b.1)，(b. 2) は， $\tilde{g}_{m, l}$ を用いて算出した $\left|d_{m}^{0}\right|$ の波形である．TS に類似した箇所では， $\left|d_{m}^{0}\right|$ の值 が 0 程度である。

図-5(c. 1)，( c. 2) は, $\left|d_{m}^{0}\right|$ と $\left|d_{m}^{0}\right|$ の差 $\left(I_{m}\right)$ を 示しており，この演算によって TS と類似する箇所 
がクローズアップされている .

図-5(d.1)，(d. 2) は， $I_{m} \geq 0$ の值を示しており， この值が大きいほど TS との相関が高い . 図-5(a. 1) において , 始点からの距離 260〜 320m 付近では $\left|\hat{d}_{m}^{0}\right|$ の值は大きいが,TS との相関が低いため,図-5(d.1) では TS 箇所に比べ $I_{m}$ が小さな結果となった .

従来の WT では, 例えば橋りょう部の段差とポッ トホールなど，路面損傷データの周波数帯域が同程 度である場合，一般的な基底関数ではこれらを識別 することが困難である．したがって，特徵的なデー タのみを抽出する場合は, 用途に応じた基底関数を 設計しなければならないが, 設計は樣々な制約条件 を満たさなければならない．また段差などの形状は 一概に規定することが難しい.

SWT は， $\tilde{s}_{k, m}$ を導入することによって特徵的な形 状を学習することができ, 用途に応じたフィルタを 作成できる . 例えば, 路面プロファイルのデータベ ースを構築した場合など, 解析データの蓄積に応じ 適宜フィルタを改良することも可能である .

（4）路面管理における第二世代ウェーブレットの 適用について

上記のように, SWT は特徵点の検出において， 従来法より優れている点が多いことがわかった . し かし本研究は基礎的な研究段階であるため，今後以 下の点について分析を進め, 路面管理における SWT の適用範囲などを整理する必要があると思われる．

・路面凹凸 (段差, ポットホール, コルゲーショ ンなど）を記録したプロファイルデータから複数 の TS を抽出し，2 章の方法によって事前に最適 な $\tilde{S}_{k, m}$ を算出する.

・特徵点は $I_{m}$ の大小によって判別するため, 特 徵点とみなすための定量的な基準を設定する .

- 初期段階における $\hat{d}_{m}^{0}$ は, WT 基底関数の種類 によって値が異なるため， $d_{m}^{0}$ との組み合わせな どを考慮した最適な基底関数を設計する．
4.まとめ

本研究は, 路面凹凸の新しい分析ツールとして SWT に着目し，PIARC EVEN 試験データを用いて 特徵点の学習及び検出について基礎的な考察を行な った. 弚の結果, 従来の WT を補完する強力な分析 ツールであることがわかった．SWT 理論を路面プ ロファイルデータ処理に応用した例としては，本 研究が国の内外を問わず最初の報告になると思われ る. 本研究で得られた知見を要約すると以下のよう になる .

- TS と形状が類似する箇所では, 出力成分がク ローズアップされる一方, 形状が異なる場合は, 振幅の大きな場合でも特徵点として検出されず， 必要な成分のみが抽出された .これは, 路面管理 目的に応じたフィルタを設計する上で, 非常に重 要な性質である .

・新たに $\tilde{g}_{m, l}$ を設計することなく，特徵点を検出 する別解法を考案した . 特徵点の検出を目的とす る場合，実用的にはこの方法で十分と考えられる． ・SWT を道路維持管理に用いる場合，段差など 路面凹凸を記録したプロファイルデータから複数 の特徵的な波形を抽出し, 路面管理目的に応じた 自由パラメータを事前に算出するなど， SWT の 適用方法を体系化する必要がある。

\section{参考文献}

1) 川村彰：路面の評価 (1)-平坦性に着目して -,舗装, Vol.36,No.8,pp.31-35,建設図書,2001.

2) 川村彰,姫野賢治,藤原隆,秋本隆: ウェーブレット 解析の路面評価問題への適用性について, 舗装工 学論文集,第 2 巻,pp.23-28,1997.

3) 日野幹雄: スペクトル解析,朝倉書店,1977.

4) 白川龍生,川村彰,上浦正樹,中辻隆：軌道メンテナ ンスへのウェーブレット理論の適用と可能性につ いて,土木計画学研究·講演集,第26 巻,No.194,2002.

5) 榊原進: ウェーブレットビギナーズカイド, 東京電 機大学出版局, 1995.

6) 芦野隆一,山本鎮男: ウェーブレット解析 誕生・ 発展・応用,共立出版, 1997.

7) W.Sweldens: The lifting scheme - A custom design construction of biorthogonal wavelets-, Appl. Comp. Harmon. Anal Vol.3(2),pp.186-200,1996.

8) S.Takano,T.Minamoto,H.Arimura,K.Niijima,T.Iyemori and T.Araki: Automatic detection of geomagnetic 
sudden commencement using lifting wavelet filters. LNAI 1721, Proc. of the Second International Conference on Discovery Science, pp.242-251, 1999.

9) S.Takano: Signal and Image Extraction by Lifting Wavelets, Doctorial Thesis, Kyushu 10)UAlivieasky,w200ura et al: Basic Analysis of measurement Data from Japan in PIARC EVEN Project,

TRB 80th Annual Meeting, 2001.

11) 白川龍生,川村彰,高橋清,中辻隆: ウェーブバンド
を考慮した路面プロファイリングデータ処理手法 について -EVEN データを用いて-,舗装工学論文 集,第 8 巻, pp.15.1-12, 2002.

12) 川村彰: PIARC 路面性状国際共通試験報告,北の 交差点,Vol.4, pp.34-35, 北海道道路管理技術センタ ,- 1998 .

13) Stephen Wolfram: The Mathematica Book Fourth Edition,東京書籍, 2000.

14) 景山克三,景山一郎: 自動車力学,理工図書,1984.

\title{
BASIC STUDY ON THE ROAD ROUGHNESS DETECTION METHOD USING THE SECOND-GENERATION WAVELET TRANSFORM
}

\author{
Tatsuo SHIRAKAWA ， Akira KAWAMURA ， Takashi NAKATSUJI and Masaki KAMIURA
}

This study proposes a method for detecting road roughness using the second-generation wavelet transform (SWT). New wavelet filters by the SWT are biorthogonal wavelet filters containing free parameters. This method

is adopted to learn free parameters based on some training signals, which contain the localized road distress. Learning wavelet filters have the special feature of the training signals and an application of the filters for the test signals leads to detection of a characteristic waveform of the road roughness effectively. 